\title{
A framework to analyse gender bias in epidemiological research
}

\author{
María Teresa Ruiz-Cantero, Carmen Vives-Cases, Lucía Artazcoz, Ana Delgado, Maria del Mar \\ García Calvente, Consuelo Miqueo, Isabel Montero, Rocío Ortiz, Elena Ronda, Isabel Ruiz, Carme \\ Valls
}

J Epidemiol Community Health 2007;61(suppl II):ii46-ii53. doi: 10.1136/jech.2007.062034

The design and analysis of research may cause systematic gender dependent errors to be produced in results because of gender insensitivity or androcentrism. Gender bias in research could be defined as a systematically erroneous gender dependent approach related to social construct, which incorrectly regards women and men as similar/different. Most gender bias can be found in the context of discovery (development of hypotheses), but it has also been found in the context of justification (methodological process), which must be improved. In fact, one of the main effects of gender bias in research is partial or incorrect knowledge in the results, which are systematically different from the real values. This paper discusses some forms of conceptual and methodological bias that may affect women's health. It proposes a framework to analyse gender bias in the design and analysis of research carried out on women's and men's health problems, and on specific women's health issues. Using examples, the framework aims to show the different theoretical perspectives in a social or clinical research context where forms of selection, measurement and confounding bias are produced as a result of gender insensitivity. Finally, this paper underlines the importance of reexamining results so that they may be reinterpreted to produce new gender based knowledge.

See end of article for authors' affiliations

Correspondence to: Maria Teresa Ruiz-Cantero, Área de Medicina Preventiva y Salud Pública, Departamento de Salud Pública, Universidad de Alicante, Apdo 99, 03080

Alicante, Spain; cantero@ va.es

Accepted 3 August 2007
Breaking with prejudices and reconstructing the object of research requires a different way of seeing, in the light of which common-sense knowledge is reconstructed as a form of bias. Ann Oakley

Gender bias is defined as the differential medical treatment of men and women, the impact of which may be positive, negative or neutral. ${ }^{2}$ For research purposes, it should be considered that research design and analysis may lead to systematic errors in the results because of gender insensitivity or androcentrism (the practice of giving overriding importance to male human beings or to the masculine point of view on the world, its culture and its history). Gender insensitivity or androcentrism are unfounded forms of prejudice. Consequently, gender bias in research could be defined as a systematic erroneous gender dependent approach related to social construct, which erroneously regards women and men as similar/ different. In turn, this bias produces mistaken or partial knowledge in the results, which are systematically different from the real values. Gender bias may cause inequitable responses from health services and discrimination against one sex or the other.

Gender bias may occur at any stage during the inferential process. Moreover, gender bias may even be found in published results, often because data are not always sex stratified. As a result, research, health promotion and preventive/healthcare services and political agendas rarely mention the processes that account for sex differences and gender inequalities.

Most gender bias is to be found in the context of discovery. ${ }^{3-5}$ The biased production of new knowledge is indirectly evidenced by the lack of research and scientific literature concerning some of the significant issues related to women's health, such as gender violence, illegal abortion and occupational health. Not indicating the susceptibility of women to certain diseases that are common in both sexes is another gender bias of knowledge, such as the false belief that more men suffer chronic obstructive pulmonary disease than women. ${ }^{6}$

Most of the research on gender bias is based on the feminist empiricism, which argues that sexism and androcentrism are forms of social bias that may be corrected by adhering more strictly to the existing methodological norms of scientific inquiry. The aim of the feminist empiricism epistemology is to remove blinders and bias in order to produce better accounts of the world. ${ }^{3-5}$ Meanwhile, the main consequence of gender bias in research is the lack of valid results. Therefore, this paper wishes to underline the need for methodological rules to be correctly applied in order to eliminate gender bias from the development of hypotheses and the interpretation stages of data so that more realistic results may be obtained..$^{3-5}$

Abbreviations: $\mathrm{AClGH}$, American Conference of Governmental Industrial Hygienists; $A O R$, adjusted odds ratios; $\mathrm{CE}$, clinical epidemiology; $\mathrm{Cl}$, confidence intervals; D, differences; DSM, Diagnostic and statistical manual of mental disorders; E, equality; EDNOS, eating disorders not otherwise specified; IRS, information retrieval system; IPV, intimate partner violence; $M B$, measurement bias; $\mathrm{MeSH}$, medical subject headings; OR, odds ratios; PTSD, posttraumatic stress disorder; RCTs, randomised controlled trials; $R R$, relative risk; $S B$, selection bias; $S E$, social epidemiology; TLVs, threshold limit values 
The international basis of evidence for professional policies and practices in health and gender research is limited and conceptual misinterpretations are common. ${ }^{8}$ This paper discusses some forms of conceptual and methodological bias that underlie research on women's health and proposes a framework for analysis. It also aims to show the importance of training health researchers in the application of the gender perspective (hypotheses and analysis of sex differences in social roles, identities, status and ideologies: androcentrism and patriarchy), in order to gain a better understanding of how gender influences the research process as regards results on the health of both sexes.

\section{GENDER INSENSITIVITY IN THE MEDLINE/PUBMED AND COCHRANE INFORMATION RETRIEVAL SYSTEM}

The bibliography selection process for any medical research and the gender perspective debate may be affected by androcentrism in traditional science. ${ }^{9}$ This is also true for the documentation sciences that are responsible for the information retrieval system (IRS). The logical basis of an IRS is the listing of descriptors that are hierarchically codified and linked with Boolean operators. Gender bias can be observed in the selection of heading terms and entry terms or in their semantic associations in the well known medical subject headings (MeSH)

An androcentric bias is the lack of a term to specifically index gender studies within the $17000 \mathrm{MeSH}$ index linked words. Neither is gender bias included among the 186 epidemiological method descriptors. This fact is considered a gender bias as the MeSH database includes less frequently used terms or unnecessary terms about other medical subjects. For instance, since 1966 the descriptor parity has been used to index studies about the women, birth rates and pregnancy. Over the past 40 years, this descriptor has only retrieved 2223 records as a major term, even after studies on diseases in the female population and during pregnancy have been added in the past few years. Another example is "vaginismus," which was introduced in 2006 as a specific MeSH term under "Sexual and Gender Pathology" in the MeSH tree. However, there are only 196 records of this term registered since 1966 and just 10 articles include this term in their title. Moreover, a year after its inclusion, only five articles have been indexed by vaginismus.

Many new and, in their semantic fields, infrequent terms have been added to the methodological branches of the MeSH tree over the past 10 years-for instance, dissents and disputes, crossover studies, fetal research-the latter in 2003, which today only has 496 records. However, gender bias transferred to prejudice despite the fact that gender bias is included in the title of 179 articles and in the abstract of 346 articles, a total of 525 records. These 179 articles on gender were classified under prejudice (84), gender identity (24), in both MeSH terms (36) and five other descriptors were used for the rest.

Our previous bibliometric studies showed that gender studies are divided among 10 different MeSH terms: prejudice, feminism, gender identity, interpersonal relationships, women's health, sex disorders and gender disorders, sex factors, sex differences and sex distributions. ${ }^{10}$ Our exhaustive search strategy retrieved 6856 articles between 1982 and 2002. Therefore, adding a generic term such as gender studies semantically related to specific terms to the MeSH database would be useful in order to make a bibliographical search easier by exploiting the term strategy. However, a series of options could be considered, such as introducing gender studies as a subheading or introducing gender bias as a specific MeSH term under patriarchal effects in the methodological branch of the $\mathrm{MeSH}$ tree.

\section{A FRAMEWORK TO ANALYSE GENDER BIAS IN RESEARCH ON WOMEN'S AND MEN'S HEALTH PROBLEMS}

Eight different theoretical and practical positions related to research that include men and women are presented within a framework (see fig 1) and are illustrated with examples or cases in order to show the relation between epidemiological bias and gender bias in a social or clinical context.

The relation between biological sex, gender as a social construct and health is complex. Perhaps as a result, the likeness of diseases and their determinants in natural and social history is unquestionably accepted, when, in fact their similarities are few (boxes 1 to 4 in fig 1). Furthermore, the existence of important differences between sexes (boxes 5 to 8 in fig 1), as well as between different groups of women and different groups of men is also accepted. These erroneous assumptions of equality or differences between sexes, in the natural history, clinical course and behaviour of diseases, may produce biased knowledge that will condition discriminatory professional practice towards one sex or the other in healthcare services, ${ }^{11}$ as well as in health promotion and preventive services and political agendas.

\section{INCORRECTLY ASSUMING EQUALITY BETWEEN WOMEN AND MEN}

One way in which health service delivery and research can involve gender bias is by assuming that women's and men's health situations and risks are similar, when in fact they are not. ${ }^{11}$

Incorrectly assuming equality between women and men (E): measurement bias (MB) in social epidemiology (SE) (box 1)

Example of familism bias

Extreme gender insensitivity in research involves ignoring sex as an important social variable. ${ }^{12}$ The aggregate bias, also known as the familism bias, frequently occurs in research on informal care. Since the family is considered to be the smallest unit of analysis, it is individually given the attribute of caring for the family unit, for instance, when it is said that "the family cares for its children and elderly," although, it is mainly the woman who carries out such tasks. Furthermore, research does not generally identify which family member carries out these reproductive tasks.

An international review of literature on elderly cancer patients and the consequences of their disease for their partners and families identified 165 references, ${ }^{13}$ some of which considered gender as a principal determinant of coping and psychological wellbeing.

The results presented were related to differences by sex (that is, differential effect of the social support received according to the sex of the patient, more emotional stress in women carers or the differences found in the use of external support), however gender analysis was not included as a key issue in the interpretation of the results. Therefore, the differing contributions that women and men made within the family and the different effects that caring for a cancer patient had on both sexes were obscured by the terms family, relatives and family members used in the review. ${ }^{13}$

Incorrectly assuming equality between women and men (E): selection bias (SB) in social epidemiology (SE) (box 2)

Example of under-representation of women in research on chemical risks

Protecting the health of workers is the aim of occupational chemical risk evaluations. However, a selection bias because of gender insensitivity may influence the threshold limit values (TLVs) of these risk evaluations, since no specific information is available regarding chemical substances and women. The TLVs 

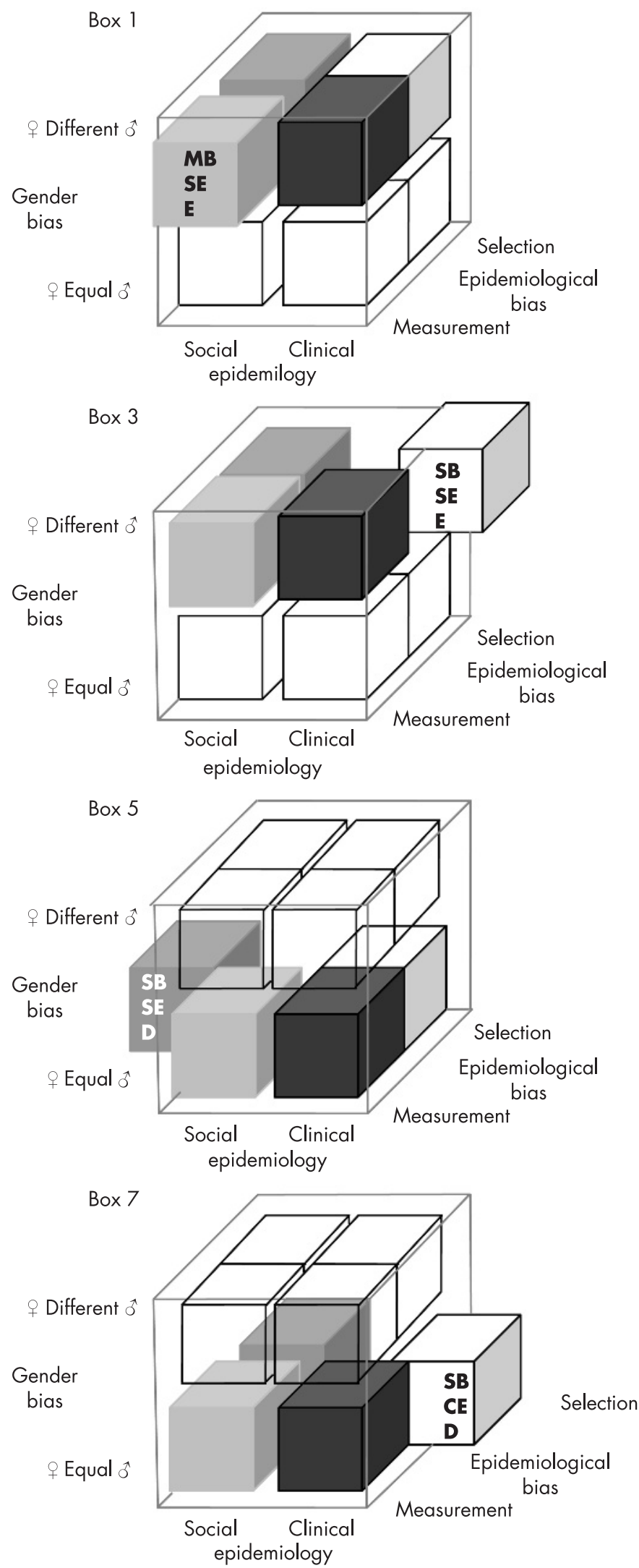

$\mathrm{SB}=$ selection bias $M B=$ measurement bias
$\mathrm{SE}=$ social epidemiology
$\mathrm{CE}=$ clinical epidemiology
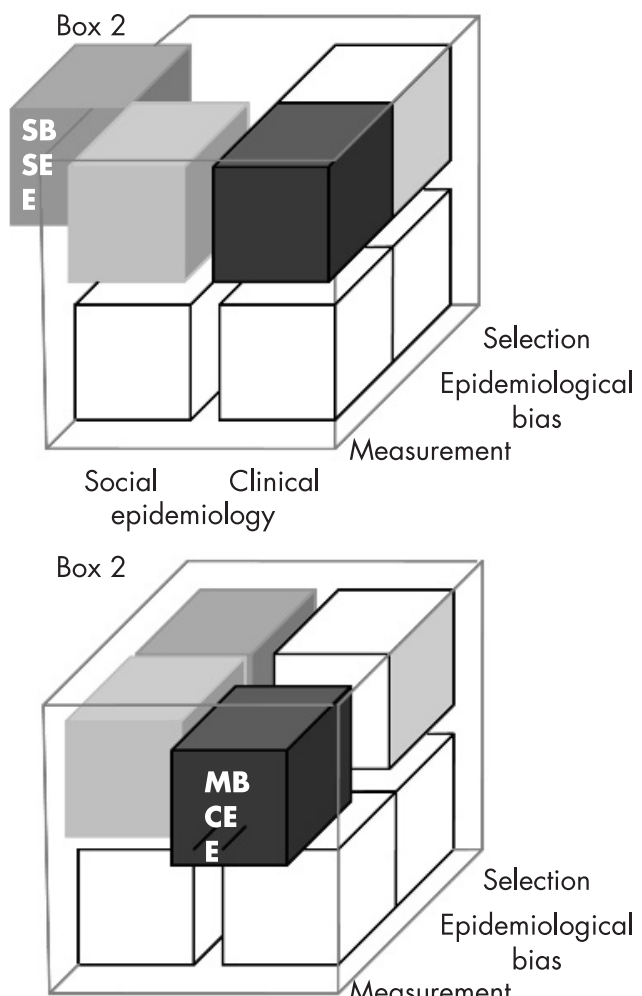

Social Clinical epidemiology

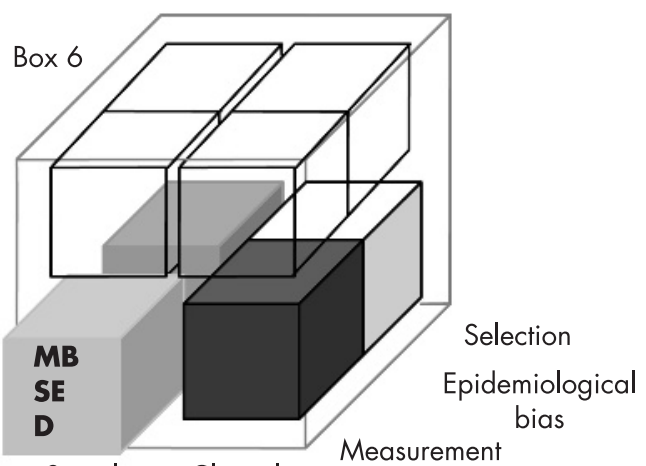

Social Clinical epidemiology

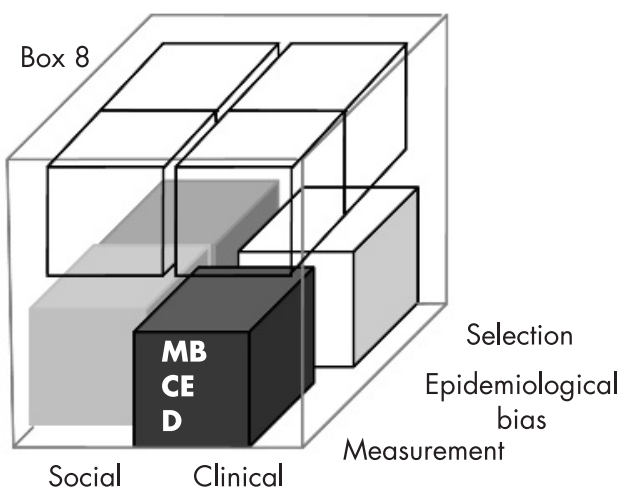
epidemiology

$\mathrm{E}=$ incorrectly assuming equality between women and men $D=$ incorrectly assuming differences between women and men

Figure 1 The three-dimensional matrix in which epidemiological bias (selection or measurement), epidemiological context (clinical or social) and gender bias (incorrectly assuming equality or differences between women and men) can be expected to influence the outcomes in a positive or negative way. 
do not consider sex differences despite the obvious metabolic differences between the sexes that may affect their reactions to exposure. Consequently, the values given are the same for both sexes in most countries as well as for the ACIGH (American Conference of Governmental Industrial Hygienists).

This is the case of the non-sex specific chemical risk evaluation in an occupation that is typical to women, hairdressing. ${ }^{14}{ }^{15}$ In addition, the reference values are not applicable as they focus on inhalation risks, and do not consider the risk of cutaneously absorbed chemicals used in this occupation. Moreover, these values have been set for specific chemicals used in an 8-hour working day, but not for chemical compounds that a hairdresser would usually use for working days that last longer than 8 hours and where work is often concentrated at the weekends and in shifts. Also, the different responses from pregnant women workers have not been taken into account in the setting of these limits. ${ }^{14} 15$

Incorrectly assuming equality between women and men (E): selection bias (SB) in clinical epidemiology (CE) (box 3)

Example of under-representation of women in clinical trials

In relation to clinical epidemiology, sex differences in pharmacokinetics and pharmacodynamics are widely recognised. ${ }^{16}{ }^{17}$ However, a classic gender selection bias in clinical research is because women are poorly represented in the samples of randomised controlled trials (RCTs) ${ }^{18-21}$ Women's participation in RCTs is lower in the early phases of the studies in which safety, a safe dosage range and side effects are determined. Fleisch et al reviewed the 2001 issues of three leading clinical pharmacology journals publishing early phase drug trials. In all, 239 studies including 15880 subjects were evaluated. Thirtyone studies tested drugs with already published differences in pharmacokinetics and adverse reactions, in only 9\% (2/22) of which had a gender specific analysis been performed. This outlines the need for women's inclusion at these early phases. ${ }^{19}$

Incorrectly assuming equality between women and men (E): measurement bias (MB) in clinical epidemiology (CE) (box 4)

Example of lack of sex stratified information in clinical trials

The lack of sex stratification could produce erroneous measurement and misleading results on the efficacy and effectiveness of drugs used for women's health. This is shown in systematic review papers. ${ }^{22}$ Furthermore, these are the cases of RCT drug therapy for myocardial infarction and rofecoxib. ${ }^{18}{ }^{20}$ In order to avoid partial knowledge on the efficacy and effectiveness of drugs in women, the following steps have been proposed ${ }^{18}$ :

- Sex distribution, which reflects the patient population likely to receive the therapy

- Subgroup analysis of men and women to permit metaanalyses

- Interaction analysis that enables differences between sexes to be determined

- Discussions that include gender related contents to establish the limits to which the results can be generalised to the population outside the trial or to underline the differences in responses by sex.

\section{INCORRECTLY ASSUMING DIFFERENCES BETWEEN WOMEN AND MEN}

The second way in which gender bias may exist in health service delivery and research is by assuming differences where there are actually similarities. ${ }^{11}$
Incorrectly assuming differences between women and men (D): selection bias (SB) in social epidemiology (SE) (box 5)

Example of gender bias related to the selection of women as subject of eating disorders studies

By analysing some recently published systematic reviews, it can be seen that studies on eating disorders involve a selection bias, as women and not men are explicitly included. ${ }^{23}{ }^{24}$ Additionally, the definition of the new Diagnostic and statistical manual of mental disorders (DSM-IV) diagnostic category known as eating disorders not otherwise specified (EDNOS) is based on the assumption that such disorders can only be found in women, ${ }^{25}$ which may thus affect the EDNOS prevalence. ${ }^{26}$

Incorrectly assuming differences between women and men (D): measurement bias (MB) in social epidemiology (SE) (box 6)

Examples of gender bias related to changes in DSM diagnostic criteria

Different reasons such as biological vulnerability, different coping styles, family history and personality traits ${ }^{27}$ among others, have been argued to explain why post-traumatic stress disorder (PTSD) may be more common in women than in men ( $13 \%$ in females and $6.2 \%$ in males $)^{28}$ when they are exposed to adverse traumatic events. One fundamental question addressed in the analyses of this sex related difference is whether differential rates of PTSD could be the result of differential exposure to events and not necessarily to differences in the development of PTSD, since the diagnosis of PTSD is dependent upon the presence of an adverse (traumatic) event.

Consideration should be given to certain new types of traumatic events not included in earlier questionnaires or scales but contained in the DSM-IV, which encompass other events beyond natural disasters, wars, torture or kidnapping. Such is the case for rape, which is obviously far more common in women than in men, as well as other forms of sexual abuse and interpersonal violence, which are also more commonly associated with PTSD when compared to accidents or natural disasters. ${ }^{29}$ In fact, women are at a greater risk of PTSD than men following exposure to rape (32\% compared to $6 \%$ in men). ${ }^{30}$ The overall risk of PTSD depends on the stressor definition and the methods used to measure exposure to specific types of traumatic events. There is consistent evidence of sex differences in the distribution of exposure across specific types of events, while different types of trauma carry different risks for the development of PTSD. As such, much of the increased prevalence of PTSD in women may be affected by trauma type. However, the assumption that women are exposed to fewer traumatic events than men is difficult to understand as an important variation across "types of traumatic events" due to information bias in the questionnaires does not inquire about relevant risks for women.

\section{Incorrectly assuming differences between women and men (D): selection bias (SB) in clinical epidemiology (CE) (box 7)}

Example of gender bias in ferritin reference values

The assumption that it is normal to find lower values for certain clinical parameters in women than in men may constitutes a gender bias that should be addressed by medicine in order to adapt the normal value or reference limits to clinical parameters of health related quality of life. ${ }^{31}{ }^{32}$ That menstruating women have up to one million red blood cells fewer than a man has been accepted as "natural" because of their monthly blood loss. It may be true that women are different from men in general but there may still be many women with undetected deficiencies. 
Table 1 Reference values of ferritin in public and private health centres in Spain

\begin{tabular}{lcrc}
\hline Public and private health centres & $\begin{array}{c}\text { Reference values } \\
\text { (ng/ml) }\end{array}$ & Women & Men \\
\hline Clinical Laboratory, Cornellá-Barcelona, Catalonia & $30-300$ & & \\
Basurto Hospital, Vasco Country & $15-150$ & & \\
Laboratory Echevarne, Granada, Andalusia & $10-204$ & & \\
San Juan de Dios Hospital, Barcelona, Catalonia & $10-120$ & $5-150$ & $20-200$ \\
La Plana Hospital, Vila-Real Valencian Community & $5-150$ & $5-140$ & $29-280$ \\
Unilabs, Barcelona, Catalonia & & $14-150$ & $40-340$ \\
Hermanos Miralles Primary Care Centre, Madrid & & $15-150$ & $30-400$ \\
Folguera Laboratory, Barcelona, Catalonia & & $20-200$ & $20-450$ \\
Fornells, Oló, Crespo Laboratory, Barcelona, Catalonia & & & \\
\hline
\end{tabular}

Based on research results, the ranges of "normal values" have changed in the past few years, which is reflected in the main internal medicine books. However, many laboratories use the euphemism "reference values," which depend on the population attended by the centre, instead of referring to "normal values." This denomination is confusing for health professionals who are required to interpret these reference values as they may be mistaken for normal values.. ${ }^{34}$ Once again, gender bias may also be the result of dispersed results of certain clinical parameters. An example of this is the wide dispersion of normal values for parameters related to bone marrow iron stores. ${ }^{35}$ Although the normal accepted value for the indicator of the iron storage protein ferritin is 50-200 ng/ $\mathrm{ml}$, it is surprising to observe the dispersion of the reference values used by different clinical analysis laboratories (table 1), with higher values in men than in women.

\section{Incorrectly assuming differences between women and men (D): measurement bias (MB) in clinical epidemiology (CE) (box 8)}

Example of gender bias measuring the delay between the onset of symptoms and obtaining treatment

Gender bias has been proved to be related to the inequitable access, use and quality of healthcare services in men and women with equal needs. Some studies on cardiology therapy and on the management of patients with chest pain, acute myocardial infarction or unstable angina measure sex differences by the time that passes between the onset of symptoms

Table 2 Multivariate odds ratios (OR) and 95\% confidence intervals $(\mathrm{Cl})$ for the associations between self perceived health status and independent variables (Catalonia Health Survey, 1994)

\begin{tabular}{|c|c|}
\hline & OR $(95 \% \mathrm{Cl})$ \\
\hline \multicolumn{2}{|l|}{ Sex } \\
\hline Men & 1 \\
\hline Women & 1.67 (1.37 to 2.03$)$ \\
\hline \multicolumn{2}{|c|}{ Occupational social class } \\
\hline Non-manual & 1 \\
\hline Manual & 2.00 (1.66 to 2.42$)$ \\
\hline \multicolumn{2}{|l|}{ Household size } \\
\hline Two & 1 \\
\hline Three & $1.08(0.75$ to 1.55$)$ \\
\hline Four & $1.39(0.98$ to 1.96$)$ \\
\hline$>$ Four & $1.58(1.08$ to 2.31$)$ \\
\hline \multicolumn{2}{|c|}{ Living with children under 15} \\
\hline No & 1 \\
\hline Yes & $0.96(0.75$ to 1.23$)$ \\
\hline \multicolumn{2}{|c|}{ Living with people older than 65} \\
\hline No & 1 \\
\hline Yes & $0.72(0.53$ to 0.98$)$ \\
\hline
\end{tabular}

and the hospital management, evaluation and therapy of the patient, and also indicate the influence of gender on this time. $^{36-38}$ For women, the overall delay in electrocardiogram time is explained by delays experienced by women with noncardiac chest pain. ${ }^{36}$ Furthermore, the higher hospital case fatality rate due to myocardial infarction in women has been related to a longer delay in reaching the hospital emergency room than men, particularly because of the role as carers of the women. ${ }^{39}$ Moreover, the impact on the pre-hospital delay time interval has been related to gender differences in reported symptoms for acute myocardial infarction. ${ }^{38}$ Most of the explanations given state that women are responsible for the delay between the onset of symptoms and their arrival at the hospital. However, the reasons for the occasional delay in healthcare assistance given to women compared to men with the same needs remain unclear and support the claim that a professional gender bias may exist. ${ }^{40}$ The IBERICA study on myocardial infarction in Spain, for example, also shows women experience longer delays from the onset of symptoms to management at hospital (120 minutes for men, 153 minutes for women). ${ }^{39}$

To prevent a possible information bias that may hamper discovering the cause behind the delay between the onset of symptoms and management at the healthcare centre, two different times should be measured: (1) the time lapse between the onset of symptoms and the request for health assistance that depends on the woman and her environment, and (2) the time lapse between the request for assistance and management that depends on the health professionals.

\section{GENDER BIAS IN THE ANALYSIS OF THE RESULTS}

In epidemiological research, certain factors are ignored repeatedly. For example, it can be said that exposure to work burden does not occur equally in men and women. In women with children, the number of hours in the workplace does not represent the total work burden to anywhere near the same extent as it would for men. Women in this situation do not rest and recuperate when they are not at work. On the contrary, for some the workplace is a relatively restful location. Also, the healthy worker effect is different in men and women: women are more strongly health selected into paid employment than men. Furthermore, the occupation given at the time of a census or survey will often not have occupied as many person years of a woman's life as it would for a man of the same age.

When insufficient information is provided in a report to determine the potentially different effects and contributions that sex may have on the research topic, a drastic review of the research design and analysis is needed. Sex is frequently treated in public health as a potentially confounding variable, the effects of which, if any, are controlled statistically and then ignored. Accordingly, data should be carefully checked to identify gender differences in health. ${ }^{41}$ 
Table 3 Multivariate odds ratios (OR) and 95\% confidence intervals (Cl) for the associations between self perceived health status and the independent variables by sex (Catalonia Health Survey, 1994)

\begin{tabular}{|c|c|c|}
\hline & \multicolumn{2}{|l|}{ OR $(95 \% \mathrm{Cl})$} \\
\hline & Men & Women \\
\hline \multicolumn{3}{|c|}{ Occupational social class } \\
\hline Non-manual & 1 & 1 \\
\hline Manual & 1.95 (1.53 to 2.48 ) & 2.07 (1.53 to 2.80$)$ \\
\hline \multicolumn{3}{|l|}{ Household size } \\
\hline Two & 1 & 1 \\
\hline Three & 0.98 (0.62 to 1.57$)$ & $1.24(0.70$ to 2.19$)$ \\
\hline Four & 1.23 (0.79 to 1.92$)$ & 1.62 (0.93 to 2.82$)$ \\
\hline$>$ Four & 1.13 (0.68 to 1.87 ) & 2.48 (1.38 to 4.46$)$ \\
\hline \multicolumn{3}{|c|}{ Living with children under 15} \\
\hline No & 1 & 1 \\
\hline Yes & 1.08 (0.79 to 1.49$)$ & $0.83(0.57$ to 1.23$)$ \\
\hline \multicolumn{3}{|c|}{ Living with people older than 65} \\
\hline No & 1 & 1 \\
\hline Yes & $0.82(0.56$ to 1.21$)$ & $0.60(0.36$ to 0.98$)$ \\
\hline
\end{tabular}

Furthermore, interactions between traditional gender roles and emerging situations may influence current trends in gender differences as regards health related behaviours and their impact on health status. ${ }^{42}$ The gender perspective must therefore be applied to the knowledge produced on the sex division of reproductive (domestic and caring) and productive work and its impact on health.

In 2001, a study was conducted on workers aged 25-64 who were married or cohabiting (2148 men and 1185 women) to examine the association between family demands and six health indicators. ${ }^{43}$ The data were taken from the 1994 Catalonian Health Survey (CHS), a cross-sectional survey based on a representative sample of the non-institutionalised population of Catalonia, a region in north eastern Spain with approximately six million inhabitants. Family demands were measured through three variables: household size, living with children under 15 and living with people older than 65 . Multiple logistic regression models and adjusted odds ratios (AOR) were fitted and 95\% confidence intervals (CI) were calculated.

Tables 2-4 illustrate why it is important that statistical analyses consider the potential interaction of gender and social class when examining variables associated with self perceived health status. In table 2, sex and occupational social class are introduced as adjusting variables, thereby assuming that the impact of family demands on health is similar for men and women and does not differ by social class. According to these results, the likelihood of reporting a poor self perceived health status increases with household size, whereas living with people older than 65 seems to be protective, regardless of sex and social class.

However, in table 3, the analysis has been stratified by sex and the results change dramatically. Household size and living with people aged over 65 can be seen to be associated only with women's health. Taking into account that women are still mainly responsible for domestic tasks, even when they are employed, these results seem to adjust better to the theoretical framework.

Resources for dealing with domestic work should be taken into account. It has been reported that hiring a person to do domestic tasks is associated with good self perceived health status among married female workers after adjusting for age and social class. No such association was found among married male workers. In fact, when the analysis is additionally stratified by social class, the impact of family demands, both as regards household size and living with people aged over 65 , is limited to women from manual social classes (table 4). Once again, these results are more coherent with the theory. Women belonging to non-manual social classes have more resources for coping with domestic work. High income enables them to pay

Table 4 Multivariate odds ratios (OR) and $95 \%$ confidence intervals (CI) for the associations between self perceived health status and independent variables by sex and occupational social class (Catalonia Health Survey, 1994)

\begin{tabular}{|c|c|c|c|c|}
\hline & \multicolumn{2}{|l|}{ Men } & \multicolumn{2}{|l|}{ Women } \\
\hline & Non-manual & Manual & Non-manual & Manual \\
\hline \multicolumn{5}{|c|}{ Household size } \\
\hline Two & 1 & 1 & 1 & 1 \\
\hline Three & 1.13 (0.54 to 2.37$)$ & 0.91 (0.49 to 1.69$)$ & $1.64(0.71$ to 3.74$)$ & $0.98(0.44$ to 2.15$)$ \\
\hline Four & $1.47(0.74$ to 2.91$)$ & 1.10 (0.60 to 2.00$)$ & 1.36 (0.60 to 3.08$)$ & 1.80 (0.83 to 3.89$)$ \\
\hline$>$ Four & $1.63(0.74$ to 3.59$)$ & 0.91 (0.46 to 1.77 ) & $2.16(0.90$ to 5.21$)$ & 2.74 (1.22 to 6.17$)$ \\
\hline \multicolumn{5}{|c|}{ Living with children under 15} \\
\hline No & 1 & 1 & 1 & 1 \\
\hline Yes & 0.77 (0.46 to 1.28$)$ & 1.37 (0.91 to 2.07$)$ & 0.66 (0.37 to 1.20$)$ & 1.05 (0.62 to 1.78 ) \\
\hline \multicolumn{5}{|c|}{$\begin{array}{l}\text { Living with people older } \\
\text { than } 65\end{array}$} \\
\hline No & 1 & 1 & 1 & 1 \\
\hline Yes & 0.88 (0.48 to 1.62$)$ & $0.77(0.47$ to 1.26$)$ & 1.15 (0.57 to 2.32$)$ & $0.33(0.16$ to 0.66$)$ \\
\hline
\end{tabular}


for help with domestic tasks and childcare and relieves them of some of the overload. Some female manual workers may be helped with domestic tasks by elderly people living at home.

The epidemiological analysis of the interactions of being employed, domestic work, gender and social class is not easy. It has been pointed out that the use of interaction terms in regression models is as adequate as stratified analysis and has the advantage of preserving parsimony. However, although this position can be defended on statistical grounds, an important part of the theoretical richness and intuitive interpretation is lost. Moreover, given the gendered nature of almost all aspects of social life, many interaction terms (some of which have more than two variables) are required in statistical models; thus making it difficult to interpret results. ${ }^{44}$

\section{EPIDEMIOLOGICAL GENDER BIAS IN SPECIFIC WOMEN'S HEALTH PROBLEMS}

Examples of bias in research on violence against women From a gender perspective, many health problems are manifestations of the asymmetrical relations of power (inequality and dominance) between men and women. This applies to intimate partner violence (IPV) against women. Because of this, the Ethics Code for Violence Research advises that women should not be exposed to risk situations even if bias is produced in research.

A selection bias was found in a cross-sectional study carried out in 23 primary health centres in Spain, which quantified IPV prevalence and measured its physical and psychological impact on health. ${ }^{45}$ The sample included 1402 randomly selected adult women attending such centres. Among the variables collected through a self administered questionnaire were the existence of physical, emotional or sexual abuse, and its timing, duration and frequency. A systematic error may have been produced, as one of the exclusion criteria was to be a woman accompanied by her partner. Consequently, the prevalence of IPV will be lower than the true prevalence as some of the excluded women could actually be suffering IPV.

In the IPV prevalence surveys, the way in which the information was obtained and its relation to the participation rate of battered women is critical. The low participation rate of battered women in household surveys may be the result of information bias, since these women tend to refuse to participate if their partner is at home in another room, or when their partner would also be interviewed. The fear of consequences of revealing their situation or the possibility of being accompanied by their partner seems to influence women in their decision not to take part in surveys. The IPV prevalence for 135 women interviewed in a street intercept survey was compared with that of a subsample of women willing to participate in a household survey. The results showed that the prevalence estimates of moderate to high IPV would be underestimated by $8 \%$ in comparison with prevalence estimates for a street intercept survey. ${ }^{46}$

The typologies of the alleged adult aggressors include those who in their childhood: (1) experienced violence from domineering parents (patriarchy), (2) witnessed and learned violent behaviour from father against mother (or vice versa) and/or against sister (sexism), and (3) neither witnessed nor experienced violence. Based on these typologies, substantial differences are found in the explicative model that relates witnessing and experiencing violence in childhood (risk factor) to exerting violence as an adult (outcome). The conflict tactics scale is the most frequently used methodological tool in measuring violent childhood experiences in men as an exposure factor, and considers witnessed or experienced violence in childhood together. ${ }^{47}$ In order to avoid misclassification bias in research on the association between being a perpetrator of IPV and having witnessed or experienced violence in childhood, the multicausal context must be taken into account. ${ }^{48}$ Accordingly, depending on the standpoint, "experiencing" and/or "witnessing" violence will be asked in separate questions or in the same one.

\section{Example of identity gender bias in research including housewives}

Gender ideology has historically underestimated or distorted the importance of the multiple contributions women have made to social production. Gender ideology can be understood as beliefs or attitudes that a person holds about gender roles: people with an egalitarian gender ideology emphasise equality and independence between men and women, while people with a more traditional gender ideology emphasise the domestic and reproductive roles of women and the productive role of men. This fact may have contributed to the existing information gap on the interaction of reproductive and productive work and its consequences on women's health.

The following case involves a study on the effects of exposure to pesticides on reproduction and illustrates how gender stereotypes may influence a biased perception of risk, making it necessary to re-analyse the information in order to identify the risks existing in women population groups that had not initially been classified as risk groups. ${ }^{49}$

When working women were compared to housewives to evaluate the effects on reproduction, worse results were observed in the housewives: low birth weight relative risk $(\mathrm{RR})=1.2(1.1$ to 1.3$)$ and preterm delivery $\mathrm{RR}=1.2$ (1.1 to 1.4). ${ }^{50}$ The possible reasons for these results are a healthy worker selection bias, differences in access to medical care during pregnancy and differences in other risk factors that could aggravate the situation. However, another explanation could be misclassification bias. Housewives could sometimes be classified as unexposed to a risk when in fact they were exposed. For instance, the great risk of fetal mortality in children of agricultural workers exposed to pesticides was $\mathrm{RR}=1.62(1.01$ to 2.60$)$. However, when this RR was stratified by the occupational status of the wives of agricultural workers exposed to pesticides (housewives vs employed women), it was higher for housewives, $\mathrm{RR}=1.68$ ( 1.03 to 2.73 ), and lower for employed women, $\mathrm{RR}=1.24$ (0.38 to 4.02$).^{51}$ These results may be due to indirect exposure (washing laundry, longer time spent at home, etc) or to the fact that the housewives may have helped their partners apply the pesticides.

\section{CONCLUSIONS}

This paper has presented a framework to show how systematic errors involving gender influence research findings. This framework has a limited structure and has been elaborated to stimulate debate in the complex area of gender and health research. Conceptual and methodological gender bias produces partial and/or invalid knowledge that affects women's health.

Gender bias is related to a general social construct, to the way researchers conceive a study, to the accuracy of results and to how these results are used to inform healthcare policy makers, as well as health care, preventive and health promotion services.

Identifying an objective and measurable bias in the management of health problems is an important aim of those researchers working in evidence based medicine and public health. Based on their experience, medical and public health professionals may be able to provide helpful hypotheses related to forms of gender bias that may occur in clinical and social research on health problems that affect both sexes or on specific women's health issues. 


\section{ACKNOWLEDGEMENTS}

We thank Cristina Domingo (Barcelona), Pilar Rallo (Jaén), Vita Arrufat (Valencia), Enriqueta Barranco (Granada) and Vicente Clemente Gómez (Alicante).

\section{Authors' affiliations}

María Teresa Ruiz-Cantero, Carmen Vives-Cases, Lucía Artazcoz, Maria del Mar García Calvente, Isabel Montero, Isabel Ruiz, Carme Valls, Red de Investigación en salud y Género, Ministerio de Sanidad y Consumo, Spain

María Teresa Ruiz-Cantero, Carmen Vives-Cases, Rocío Ortiz, Elena

Ronda, Medicina Preventiva y Salud Pública, Universidad de Alicante, Spain

Lucía Artazcoz, Agencia de Salud Pública de Barcelona, Spain Ana Delgado, Maria del Mar García Calvente, Escuela Andaluza de Salud Pública, Granada, Spain

Consuelo Miqueo, Departamento de Ciencias Documentación e Historia de la Ciencia, Universidad de Zaragoza, Spain

Isabel Montero, Departamento de Medicina, Universidad de Valencia,

Spain

Carme Valls, Centro de Análisis y Planificación Sanitaria, Barcelona,

Spain

María Teresa Ruiz-Cantero, Carmen Vives-Cases, Lucía Artazcoz,

CIBERESP, Spain

Funding: This work has been financed by the Spanish Research Network on Health and Gender (RISG).

\section{REFERENCES}

1 Oakley A. Experiments in knowing. Gender and method in the social sciences. Cambridge: Polity Press, 2000.

2 Lenhart Sh. Gender discrimination: A health and career development problem for women physicians. J Am Med Women Assoc 1993;48:155-9

3 Harding S. The science question in feminism. New York: Cornell University Press, Ithaca, 1993.

4 Harding S. Feminism and methodology: social science issues. Bloomington, IN Indiana University Press, 1987.

5 Harding S. Whose science, whose knowledge? New York: Cornell University Press Ithaca, 1991.

6 Chapman KR, Tashkin D, Pye DJ. Gender bias in the diagnosis of COPD. Chest 2001;119:1691-5.

7 Miravitlles M, de la Roza C, Naberan K, et al. Attitudes toward the diagnosis of chronic obstructive pulmonary disease in primary care. Arch Bronconeumol 2006;42:3-8.

8 Doyal L. Sex and gender: the challenges for epidemiologists. Int J Health Serv 2003;33:569-79.

9 Miqueo C. Women and doctors in medicine. Lancet 1999;354:65.

10 Miqueo C, Barral MJ, Fernandez T, et al. Progresividad del proyecto género en salud. Análisis bibliométrico de la literatura internacional: 1982-2002. In: Pérez Sedeño E, ed. Ciencia, tecnología y género en Iberoamerica. Madrid: CSIC, 2006.

11 Ruiz MT, Verbrugge L. A two way view of gender bias in medicine. J Epidemiol Comm Health, 1997;51:106-9.

12 Eichler M. Non-sexist research methods. A practical guide. New York: Routledge, 1991

13 Kotkamp-Mothes N, Slawinsky D, Hinderman S, et al. Coping and psychological well being in families of elderly cancer patients. Crit Rev Oncol Hematol 2005;55:213-29

14 Van der Wal JF, Hoogeveen AW, Moons AMM, et al. Investigation on the exposure of hairdressers to chemical agents. Environ Int 1997;23:433-9.

15 Labreche F, Forest J, Trottier M, et al. Characterization of chemical exposures in hairdressing salons. Appl Occup Environ Hyg 2003;18:1014-21.

16 Gandhi M, Aweeka F, Greenblatt R, et al. Sex differences pharmacokinetics and pharmacodynamics. Annu Rev Pharmacol Toxicol 2004;44:499-523.

17 European Medicines Agency. Gender considerations in the conduct of clinical trials (EMEA/CHMP/3916/2005). http://www.emea.eu.int/pdfs/human/ich/ 391605en.pdf (accessed 9 July 2007).

18 Rochon PA, Clark JP, Binns MA, et al. Reporting of gender-related information in clinical trials of drug therapy for myocardial infarction. CMAJ 1998;159:321-7.
19 Fleish J, Fleish M, Thürmann P. Women in early-phase clinical drug trials. Have things changed over the past 20 years? Clin Pharmacol Ther 2005:78:445-52

20 Cascales S, Ruiz Cantero MT, Pardo MA. Clinical trials with rofecoxib: analysis of the information from the gender perspective. Med Clin (Barc) 2003; 120:207-12.

21 Ruiz Cantero MT, Pardo MA. European Medicines Agency policies for clinical trials leave women unprotected. J Epidemiol Comm Health 2006;60:91 1-3.

22 Vidaver RM, LaFleur B, Tong C, et al. Women subjects in NHI-funded clinical research literature: lack of progress in both representation and analysis by sex. $J$ Womens Health Gend Based Med 2000;9:495-504.

23 Hoek HW, Van Hoeken D. Review of the prevalence and incidence of eating disorders. Int J Eat Disord 2003;34:383-96.

24 Peláez-Fernández MA, Labrador-Encinas FJ, Raich-Escursell RM. Epidemiología de los trastornos de la conducta alimentaria en España: revisión y estado de la cuestión. C Med Psicosom 2004;71-72:33-41.

25 American Psychiatric Association. Diagnostic and statistical manual of mental disorders. Washington: APA, 1994.

26 Machado PP, Machado BC, Goncalvez S, et al. The prevalence of eating disorders not otherwise specified. Int J Eat Disord 2007:40:212-21.

27 Hembree EA, Foa EB. Post-traumatic stress disorder: psychological factors and psychosocial interventions. J Clin Psychiatry 2000;61(suppl 7):33-99.

28 Breslau N, Davis GC, Andreski P, et al. Sex differences in post-traumatic stress disorder. Arch Gen Psychiatry 1997:54:1044-8.

29 Mechanic MB. Beyond PTSD: mental health consequences of violence against women. J Interpers Violence 2004;19:1283-9.

30 Norris FH. Epidemiology of trauma: frequency and impact of different potentially traumatic events on different demographic groups. J Consult Clin Psychol 1992;60:409-18.

31 Hastka J, Laserre JJ, Schwarzbeck A, et al. Laboratory tests of iron status: correlation or common sense? Clin Chem 1996;42:657.

32 Rushton DH, Dover R, Sainsbury AW, et al. Iron deficiency is neglected in women's health. BMJ 2002;325:1176.

33 Naghii MR, Fouladi Al. Correct assessment of iron depletion and iron deficiency anemia. Nutr Health 2006;18:133-9.

34 Hillman RS, Finch CA. Red cell manual. Philadelphia: Davis, 1996.

35 Kasper DL, Braunwald E, Fauci A, et al. Harrison's principles of internal medicine. New York: McGraw-Hill, 2004.

36 Takakuwa KM, Shofer FS, Hollander JE. The influence of race and gender on time to initial electrocardiogram for patients with chest pain. Acad Emerg Med 2006;13:867-72.

37 Rosenfeld AG, Lindauer A, Darney BG. Understanding treatment-seeking delay in women with acute myocardial infarction: descriptions of decision-making patterns. Am J Crit Care 2005;14:285-93

38 Meischke H, Larsen MP, Eisenberg MS. Gender differences in reported symptoms for acute myocardial infarction: impact on prehospital delay time interval. Am J Emerg Med 1998;16:363-6.

39 Segura A, Zurriaga O, Rohlfs I, et al. Diferencias por género en las características, manejo y letalidad-complicaciones en pacientes con infarto agudo de miocardio (IAM): Estudio IBERICA. Gac Sanit 2002;16(Suppl 1):90.

40 Ruiz MT, Ronda E, Gil VF, et al. Atención según el género del paciente en los servicios de urgencias: ¿diferente o desigual? Gac Sanit 1995;9:76-83.

41 Stephenson P, McKee M. Look twice. Eur J Publ Health 1993;3:151-2.

42 Annandale E, Hunt K. Gender inequalities in health. Buckingham: Open University Press, 2000

43 Artazcoz L, Borrell C, Benach J. Gender inequalities in health among workers: the relation with family demands. J Epidemiol Comm Health 2001;55:639-47.

44 Kunkel SR, Atchely RC. Why gender matters: being female is not the same as not being male. Am J Prev Med 1996;12:294-6.

45 Ruiz-Perez I, Plazaola-Castaño J, Blanco-Prieto $P$, et al. Intimate partner violence. A survey conducted in the primary care setting. Gac Sanit 2006;20:202-8.

46 Waltermaurer E, Ortega C, McNutt L. Issues in estimating the prevalence of intimate partner violence. Assessing the impact of abuse status on participation bias. J Interpers Violence 2003;18:959-74.

47 Strauss MA, Hamby SL, Boney-McCoy S, et al. The revised conflict tactics scales (CTS2). Development and preliminary psychometric data. J Fam Issues 1996;17:283-316.

48 Heise L. Violence against women. An integrated, ecological framework. Violence Against Women 1998;4:262-90.

49 Murphy JF, Dauncey M, Newcombe R. Employment in pregnancy: prevalence, maternal characteristics, perinatal outcome. Lancet 1984;26:1 163-6.

50 Regidor E, Ronda E, García AM, et al. Paternal exposure to agriculture pesticides and cause specific of foetal death. J Occup Environ Med 2004:61:334-9.

51 Ronda E, Regidor E, García AM, et al. Association between congenital anomalies and paternal exposure to agriculture pesticides depending on mother's employment status. J Occup Environ Med 2005;47:826-8. 